\title{
Resource Constraints as a Barrier to Lung Cancer Management: Developing Nations
}

\author{
Sumitra Thongprasert ${ }^{1}$, Unchalee Permsuwan ${ }^{2 *}$ \\ ${ }^{1}$ Faculty of Medicine, Chiang Mai University, Chiang Mai, Thailand \\ ${ }^{2}$ Faculty of Pharmacy, Chiang Mai University, Chiang Mai, Thailand \\ Email: ${ }^{*}$ unchalee.permsuwan@gmail.com
}

Received 22 January 2014; revised 26 February 2014; accepted 6 March 2014

Copyright (C) 2014 by authors and Scientific Research Publishing Inc.

This work is licensed under the Creative Commons Attribution International License (CC BY). http://creativecommons.org/licenses/by/4.0/

(c) $\underset{\mathrm{EY}}{\mathrm{B}}$ Open Access

\begin{abstract}
Resource constraints are a major barrier to lung cancer management, especially in ASIAN developing countries. The availability of data in these issues is very limited. Therefore, this survey was initiated in order to understand the situation of resource constraints in ASIAN developing nations. A 17-item, self-administered, online questionnaire was developed and distributed to IASLC members in ASIAN countries in May-June 2013. A questionnaire was composed of 2 sections: general and specific information focusing on several issues related to resource constraints such as lagging period of new cancer drug approval, economic data submission, man power, availability and accessibility to diagnosis and treatment, waiting time, and payment. There were a total of 75 respondents from China, India, Indonesia, Malaysia, Nepal, Philippines, and Thailand. The findings of this survey demonstrate that ASIAN developing countries still need the improvement in their resources such as man power, diagnostic procedures, and treatment especially new agents like targeted drugs.
\end{abstract}

Keywords

Resource Constraint; ASIAN; Lung Cancer Management

\section{Introduction}

Lung cancer is the most commonly diagnosed cancer in low- and middle-income countries and the single most significant cause of cancer-related death [1]. Given the high incidence of lung cancer in ASIA, the resource allocation for lung cancer management has been low as comparing to global lung cancer spending [2]. To be effective lung cancer treatment, services must have enough resources including effective diagnostic tools, cancer

${ }^{*}$ Corresponding author. 
drugs, healthcare personnel, and organizational infrastructure. To achieve the goal of successful providing care for lung cancer patients, some key elements should be taken into consideration [2]. Each country should have their national planning based on qualified information on their resources. Healthcare systems should be strengthened together with provider training improvement. Positive treatment outcomes are provided through improved education of health professionals and the public. It is necessary to improve the accessibility to traditional treatment approaches including chemotherapy, radiotherapy, surgery, and quality palliative care. Additionally, the accessibility needs to be broadened to newer treatment such as targeted therapies.

In ASIAN developing countries, there are a paucity of data regarding the personnel treating lung cancer, waiting time for diagnosis and treatment, accessibility and availability of expensive treatment including targeted agents and so on. Policy makers often remain unaware of the deficit of resources in their countries. Hence, this study was initiated in order to answer these deficits so that policy makers would have additional useful information.

\section{Aims}

This study was initiated in order to survey the real ASIAN situation regarding resources in lung cancer management. We were focusing on the ASIAN developing countries such as China, India, Indonesia, Malaysia, Nepal, Philippines, and Thailand.

\section{Methods}

\subsection{Questionnaire}

A 17-item, self-administered, online questionnaire was developed. It was composed of two sections: general information (7 items) and specific information (10 items). For general information, items were related to age, gender, countries, and type of professionals, years of experiences, working place, and health insurance scheme in their countries. Specific items focused on seven aspects: 1) lagging period of new cancer drug approval; 2) submission of economic analysis; 3) sufficient man power; 4) availability of cancer drugs; 5) accessibility to cancer drugs; 6) waiting time to undergo advanced diagnostic tools and cancer treatment; and 7) payment responsibility. For specific information from part 4 to part 7, the answer was divided into five levels of Likert scales. Other questions provided with multiple choices to select the most likely answer for respondents.

Content validity of developed questionnaire was performed by several experts in oncology and health economists through direct contact. Then, we revised our questionnaire according to their suggestion to obtain the final version.

\subsection{Data Collection}

An online questionnaire was distributed to IASLC members in ASIAN countries by the support of IASLC office. It took less than 5 minutes to complete an online questionnaire. The link was protected so that each respondent could complete the survey only once. The survey was performed in May-June 2013.

\subsection{Statistical Analysis}

All general and specific information data were analyzed using description statistics. We used SPSS version 17.0 for data analysis.

\section{Results}

\subsection{General Information}

There were a total of 75 respondents from 7 countries. Of those 75 respondents, 32, 15, 2, 6, 2, 4, and 14 are from China, India, Indonesia, Malaysia, Nepal, Philippines, and Thailand respectively. Their general information was demonstrated in Table 1.

Health insurance beneficiaries were from private insurance, government insurance, out of pocket, and social worker benefit scheme. Most countries, except for Malaysia and Nepal, reported government provided health insurance. Private insurance and out of pocket were reported in all countries. Social worker benefit scheme was not available only in Nepal. 
Table 1. General information of respondents.

\begin{tabular}{|c|c|c|c|c|c|c|c|c|}
\hline \multirow{2}{*}{ Variables } & \multicolumn{7}{|c|}{ Number (\%) } & \multirow{2}{*}{$\begin{array}{c}\text { Total } \\
(\mathrm{n}=75)\end{array}$} \\
\hline & $\begin{array}{c}\text { China } \\
(\mathrm{n}=32)\end{array}$ & $\begin{array}{c}\text { India } \\
(n=15)\end{array}$ & $\begin{array}{c}\text { Indonesia } \\
(\mathrm{n}=2)\end{array}$ & $\begin{array}{c}\text { Malaysia } \\
(\mathrm{n}=6)\end{array}$ & $\begin{array}{l}\text { Nepal } \\
(\mathrm{n}=2)\end{array}$ & $\begin{array}{l}\text { Philippines } \\
\quad(\mathrm{n}=4)\end{array}$ & $\begin{array}{l}\text { Thailand } \\
(\mathrm{n}=14)\end{array}$ & \\
\hline \multicolumn{9}{|l|}{ Gender } \\
\hline Male & $22(68.8 \%)$ & 13 (92.9\%) & $1(50.0 \%)$ & $6(100.0 \%)$ & $2(100.0 \%)$ & $1(25.0 \%)$ & $5(35.7 \%)$ & $50(67.6 \%)$ \\
\hline Female & 10 (31.3\%) & 1 (7.1\%) & $1(50.0 \%)$ & $0(0.0 \%)$ & $0(0.0 \%)$ & $3(75.0 \%)$ & $9(64.3 \%)$ & $24(32.4 \%)$ \\
\hline \multicolumn{9}{|l|}{ Age } \\
\hline$\leq 40$ years & $8(27.6 \%)$ & $6(42.9 \%)$ & $0(0.0 \%)$ & $1(16.7 \%)$ & $2(100.0 \%)$ & $0(0.0 \%)$ & $6(50.0 \%)$ & $23(34.3 \%)$ \\
\hline 41 - 50 years & 15 (51.7\%) & $2(14.3 \%)$ & $1(100.0 \%)$ & $3(50.0 \%)$ & $0(0.0 \%)$ & $2(66.7 \%)$ & $2(16.7 \%)$ & 25 (37.3\%) \\
\hline 51 - 60 years & $5(17.2 \%)$ & $5(35.7 \%)$ & $0(0.0 \%)$ & $2(33.3 \%)$ & $0(0.0 \%)$ & $1(33.3 \%)$ & $4(33.3 \%)$ & $17(25.4 \%)$ \\
\hline$>60$ years & $1(3.4 \%)$ & $1(7.1 \%)$ & $0(0.0 \%)$ & $0(0.0 \%)$ & $0(0.0 \%)$ & $0(0.0 \%)$ & $0(0.0 \%)$ & $2(3.0 \%)$ \\
\hline \multicolumn{9}{|l|}{ Professional } \\
\hline Medical oncologist & 12 (37.5\%) & $3(20.0 \%)$ & $0(0.0 \%)$ & $0(0.0 \%)$ & $0(0.0 \%)$ & $3(75.0 \%)$ & $5(35.7 \%)$ & $23(30.7 \%)$ \\
\hline Pulmonologies & $4(12.5 \%$ & $2(13.3 \%)$ & $1(50.0 \%)$ & $6(100.0 \%)$ & $0(0.0 \%)$ & $0(0.0 \%)$ & $2(14.3 \%)$ & $15(20.0 \%)$ \\
\hline Radiologist & $0(0.0 \%)$ & $0(0.0 \%)$ & $0(0.0 \%)$ & $0(0.0 \%)$ & $0(0.0 \%)$ & $0(0.0 \%)$ & $1(7.1 \%)$ & $1(1.3 \%)$ \\
\hline Radiation oncologist & $3(9.4 \%)$ & $5(33.3 \%)$ & $0(0.0 \%)$ & $0(0.0 \%)$ & $1(50.0 \%)$ & $0(0.0 \%)$ & $5(35.7 \%)$ & $14(18.7 \%)$ \\
\hline Thoracic surgeon & 12 (37.5\%) & $1(6.7 \%)$ & $0(0.0 \%)$ & $0(0.0 \%)$ & $1(50.0 \%)$ & $0(0.0 \%)$ & $1(7.1 \%)$ & $15(20.0 \%)$ \\
\hline Others & $1(3.1 \%)$ & $4(26.7 \%)$ & $1(50.0 \%)$ & $0(0.0 \%)$ & $0(0.0 \%)$ & $1(25.0 \%)$ & $0(0.0 \%)$ & 7 (9.3\%) \\
\hline \multicolumn{9}{|c|}{ Experience in oncology area } \\
\hline$<5$ years & $2(6.3 \%)$ & $2(13.3 \%)$ & $0(0.0 \%)$ & $1(16.7 \%)$ & $1(50.0 \%)$ & $0(0.0 \%)$ & $2(14.3 \%)$ & $8(10.7 \%)$ \\
\hline 5 - 10 years & $1(3.1 \%)$ & $4(26.7 \%)$ & $0(0.0 \%)$ & $2(33.3 \%)$ & $1(50.0 \%)$ & $1(25.0 \%)$ & $5(35.7 \%)$ & $14(18.7 \%)$ \\
\hline 11 - 20 years & $10(31.3 \%)$ & $3(20.0 \%)$ & $2(100.0 \%)$ & $2(33.3 \%)$ & $0(0.0 \%)$ & $2(50.0 \%)$ & $4(28.6 \%)$ & $23(30.7 \%)$ \\
\hline$>20$ years & 19 (59.4\%) & $6(40.0 \%)$ & $0(0.0 \%)$ & $1(16.7 \%)$ & $0(0.0 \%)$ & $1(25.0 \%)$ & $3(21.4 \%)$ & $30(40.0 \%)$ \\
\hline \multicolumn{9}{|l|}{ Working place } \\
\hline Government hospital & 15 (46.9\%) & $4(26.7 \%)$ & $2(100.0 \%)$ & $4(66.7 \%)$ & $1(50.0 \%)$ & $2(50.0 \%)$ & $7(50.0 \%)$ & $35(46.7 \%)$ \\
\hline Private hospital & $0(0.0 \%)$ & $4(26.7 \%)$ & $0(0.0 \%)$ & $0(0.0 \%)$ & $0(0.0 \%)$ & $2(50.0 \%)$ & $1(7.1 \%)$ & 7 (9.3\%) \\
\hline University hospital & $17(53.1 \%)$ & $5(33.3 \%)$ & $0(0.0 \%)$ & $2(33.3 \%)$ & $1(50.0 \%)$ & $0(0.0 \%)$ & $6(42.9 \%)$ & $31(41.3 \%)$ \\
\hline Others & $0(0.0 \%)$ & $2(13.3 \%)$ & $0(0.0 \%)$ & $0(0.0 \%)$ & $0(0.0 \%)$ & $0(0.0 \%)$ & $0(0.0 \%)$ & 2 (2.7\%) \\
\hline
\end{tabular}

\subsection{Drug Approval Period}

Most countries responded that the lagging period from the FIRST global cancer drug approval to each country approval was about 1 - 5 years. The period after submission to obtain new cancer drug approval lasted about 6 months to 1 year in most countries, except for China and Thailand where the period took $>1$ - 2 years. China, India, Indonesia, and Thailand required economic study submission in the submission package for cancer drug approval.

\subsection{Man Power}

All countries responded to the question about man power alike in that there were not sufficient manpower in medical oncologists, radiation oncologist, pulmonologists, thoracic surgeons, radiologists, nurses, and pharmacists. 


\subsection{Drug Availability and Accessibility}

All countries had moderate to high availability of chemotherapeutic drugs. Accessibility to these drugs were at the level of moderate to high in all countries except for Indonesia where the accessibility was still low. Targeted drugs, on the other hand, had low to moderate availability and accessibility in most countries. China was the only country that indicated more than $50 \%$ of high level of targeted drugs availability (Figure 1).

\subsection{Waiting Time}

All countries had similar waiting time for CT scan which was less than 4 weeks. Waiting time was longer for MRI and PET scan which was up to 8 weeks. For bone scan, Thailand and Nepal had longer waiting time (more than 8 weeks) compared to the other countries. China had less waiting time for receiving diagnostic work up from those tools compared to other countries (Figure 2).

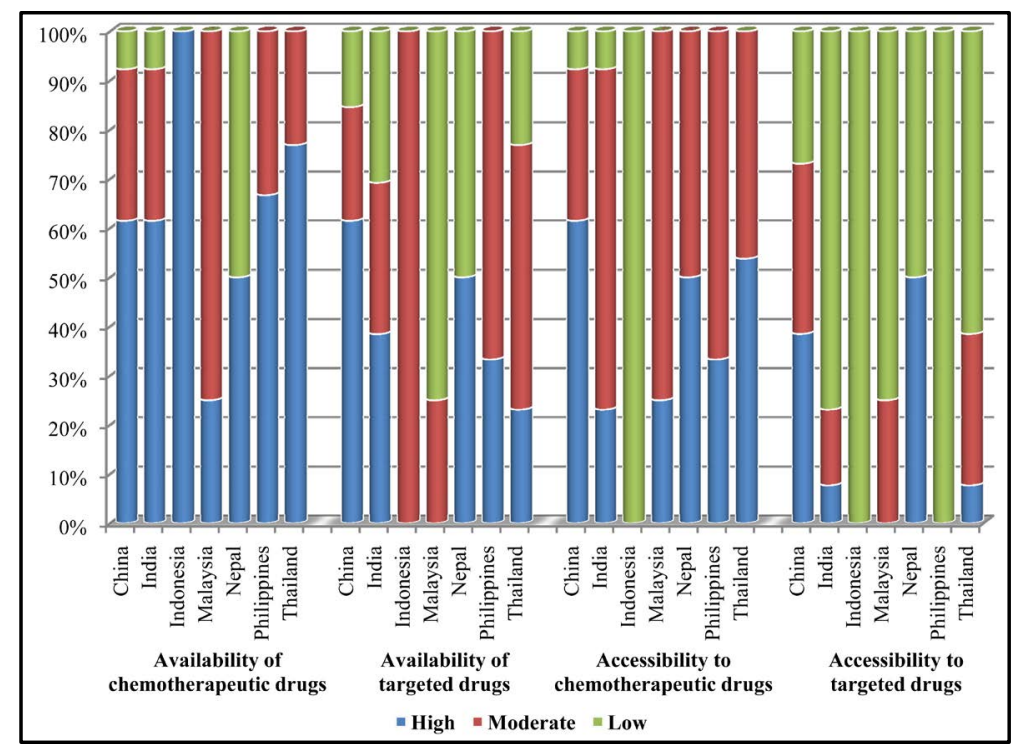

Figure 1. Availability and accessibility of cancer drugs.

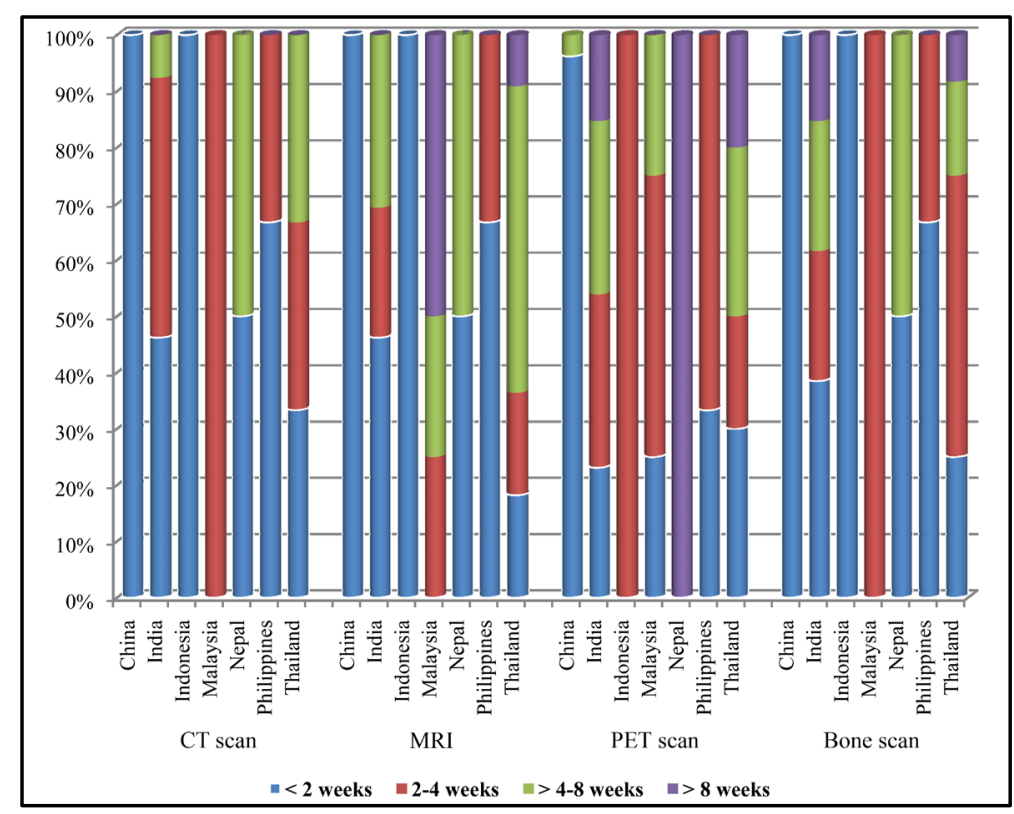

Figure 2. Waiting time to receive cancer diagnosis by imaging. 
Direct lung tap, thoracentesis/pleural biopsy, lymph node biopsy, bronchoscope were the frequent diagnostic procedures which were available and accessible in all countries within 2 weeks. Endobronchial ultrasound, Endoscopic Ultrasound (EUS), Video-Assisted Thoracic Surgery (VATS) had longer waiting time than above procedures, usually around 4 weeks, except for China where the procedures were performed within less than 2 weeks (Figure 3).

For cancer chemotherapy, China, Indonesia and Nepal had less than 2 weeks of waiting time. However, the waiting time was longer in other countries including India, Malaysia, Philippines and Thailand (Figure 4). Compared with chemotherapy, targeted agents had longer waiting time. The treatment procedures were provided within less than 4 weeks in most countries. Waiting time for radiotherapy and surgery were generally longer than that of chemotherapy in most countries (Figure 4).

\subsection{Payment Responsibility}

Figure 5 showed the payment responsibility scheme for the lung cancer treatment. Approximately $70 \%$ of lung

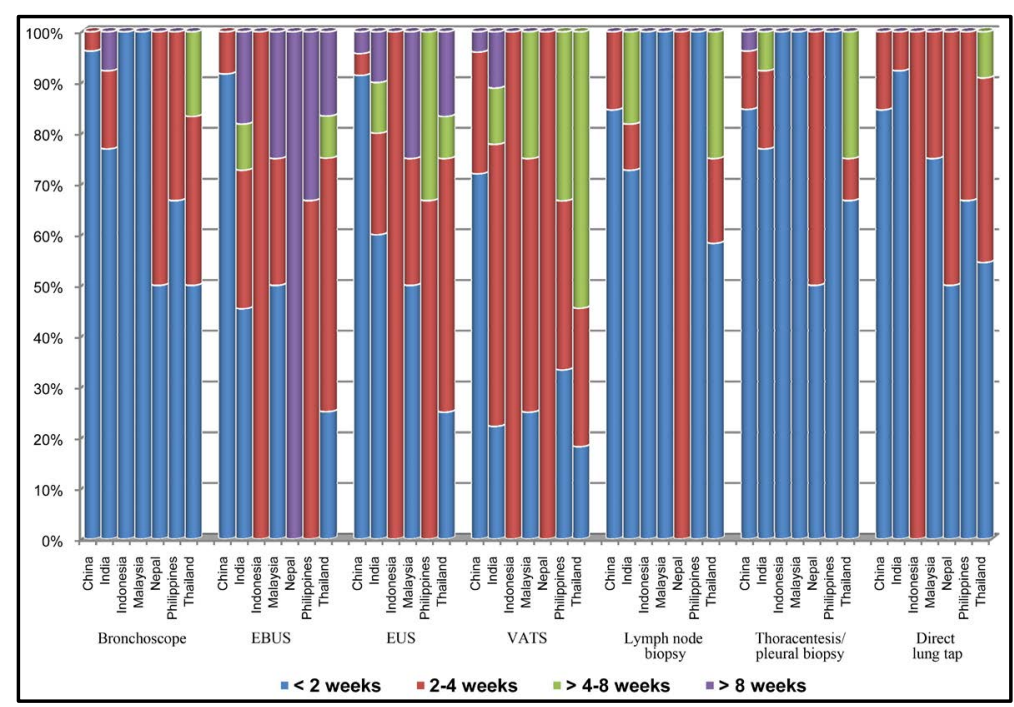

Figure 3. Waiting time to receive cancer diagnosis by diagnostic procedures.

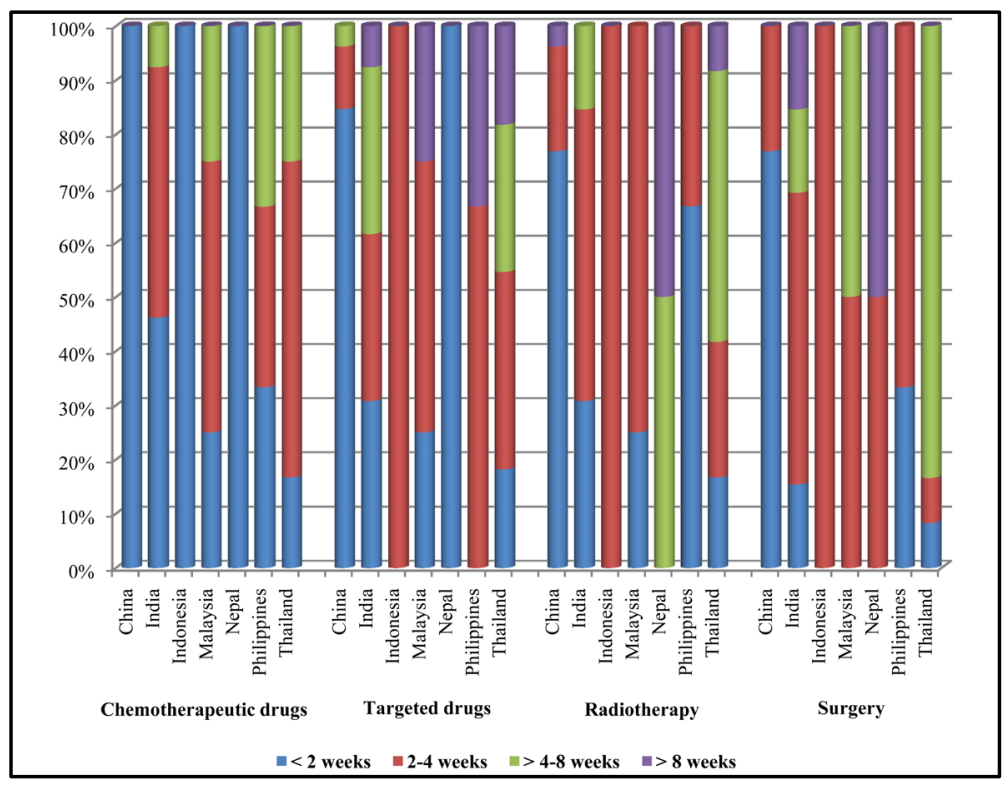

Figure 4. Waiting time to receive cancer treatment. 


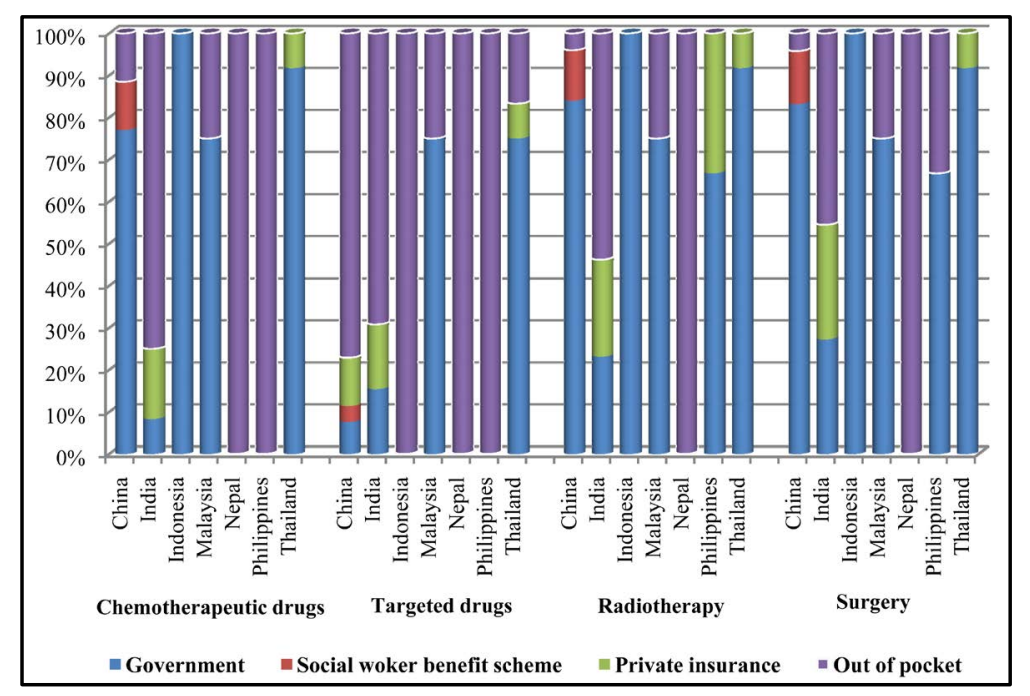

Figure 5. Payment scheme for cancer treatment.

cancer surgery, radiotherapy, and chemotherapy were paid by government in all countries except for India, Nepal. For those 2 countries, patients had to pay out of their own pocket. Targeted drugs were less covered by government compared to chemotherapy in most countries except for Malaysia and Thailand.

Regarding diagnostic work up such as CT, MRI, and Bone Scan, most countries specified that costs were covered by government insurance except for Nepal and Philippines. However, PET scan was mostly paid by patients or private insurance.

Diagnostic procedures such as Bronchoscope, Lymph node biopsy, Thoracentesis-Pleural Biopsy were paid by government insurance. However, EBUS, EUS and VATS were paid by either government or private insurances.

\section{Discussion}

Several limitations needed to address in this survey. First, due to a short survey period, we received responses from few respondents in some countries such as Nepal (only 2 respondents). Second, some issues in the questionnaire might not elucidate to all respondents leading to inaccurate answer. Third, there was imbalance in the number of respondents and their subspecialties in each country. Fourth, the questionnaire was not directly specific for the available of the equipment, thus this information was lacking. However, we believe that our findings might have some benefit and encourage health care providers in ASIAN developing nations to improve their resource allocation.

Currently, most countries have no plan available to address these deficits. Access to effective but unfunded cancer drugs varies across Asian developing countries. Policymakers need to consider whether this resource constraint reported here is consistent with articulated values of their system. There is a paucity of evidence related to the actual deficit of resources in cancer treatment especially lung cancer in Asian developing countries. Radiation therapy guideline of lung cancer treatment was provided by the International Atomic Energy Agency (IAEA) to assist oncologists in developing countries with markedly fewer resources than the developed world [3]. However this guideline did not indicate the level of resource limitation. Same problem occurred with diagnostic method and the treatment with chemotherapy or targeted drug. Regarding the expensive drug, in developing countries like Canada [4], the access to effective but unfunded cancer drugs varies across the country. Thus, there is unmet need to consider the merits of the different means of accessing these drugs to appropriately and fairly integrate access into publically funded health care systems [5] [6].

\section{Conclusion}

The findings of this survey demonstrate that ASIAN developing countries still need the improvement in their resources such as man power, diagnostic procedures, and treatment especially new agents like targeted drugs. In order to comprehend the shortage of cancer diagnosis and treatment, each developing country might need to 
conduct in depth research in this area.

\section{Acknowledgements}

We very much appreciate Ms. Kristin Richeimer, Director of Membership International Association for the Study of Lung Cancer (IASLC) for her assistance of formatting and distributing an online questionnaire, and gathering the data.

\section{References}

[1] International Agency for Research on Cancer. GLOBOCAN. (2012) Estimated Cancer Incidence, Mortality and Prevalence Worldwide in 2012. http://globocan.iarc.fr/Pages/fact_sheets_cancer.aspx

[2] Knaul, F.M., Anderson, B., Bradley, C. and Kerr, D. (2010) Access to Cancer Treatment in Low- and Middle-Income Countries. An Essential Part of Global Cancer Control. http://papers.ssm.com/sol3/papers.cfm?abstract_id=2055441

[3] Macbeth, F.R., Abratt, R.P., Choc, K.H., Stephens, R.J. and Jeremice, B. (2007) International Atomic Energy Agency Lung Cancer Management in Limited Resource Settings: Guidelines for Appropriate Good Care. Radiotherapy and Oncology, 82, 123-131. http://dx.doi.org/10.1016/j.radonc.2006.12.006

[4] Berry, S.R., Evans, W.K., Strevel, E.L. and Bell, C.M. (2012) Variation and Constemation: Access to Unfunded Cancer Drugs in Canada. Journal of Oncology Practice, 8, 135-139. http://dx.doi.org/10.1200/JOP.2011.000278

[5] Farmer, P., Frenk, J., Knaul, F.M., Shulman, L.N., Alleyne, G., Armstrong, L., et al. (2010) Expansion of Cancer Care and Control in Countries of Low and Middle Income: A Call to Action. Lancet, 376, 1186-1193. http://dx.doi.org/10.1016/S0140-6736(10)61152-X

[6] Pickles, H. (1997) Treating Lung Cancer in the NHS Market. British Medical Journal, 315, 1548.2. 